\section{Lithium Cadmate-Mediated Deprotonative Metalation of Anisole: Experimental and Computational Study}

\author{
Katia Snégaroff, ${ }^{\dagger}$ Shinsuke Komagawa, ${ }^{\ddagger}$ Mitsuhiro \\ Yonehara, ${ }^{\ddagger}$ Floris Chevallier, ${ }^{\dagger}$ Philippe C. Gros, ${ }^{\S}$ \\ Masanobu Uchiyama* ${ }^{* \dagger}$ and Florence Mongin* ${ }^{*}$, \\ ${ }^{\dagger}$ Chimie et Photonique Moléculaires, UMR 6510 CNRS, \\ Université de Rennes 1, Bâtiment 10A, Case 1003, Campus \\ Scientifique de Beaulieu, 35042 Rennes, France, ${ }^{\star}$ The \\ Institute of Physical and Chemical Research, RIKEN, 2-1 \\ Hirosawa, Wako-shi, Saitama 351-0198, Japan, and ${ }^{\S}$ SOR, \\ SRSMC, CNRS, Université de Nancy, Boulevard des \\ Aiguillettes, 54506 Vandouvre-Lès-Nancy, France
}

uchi_yama@riken.jp,florence.mongin@univ-rennes1.fr

\section{RECEIVED DATE}

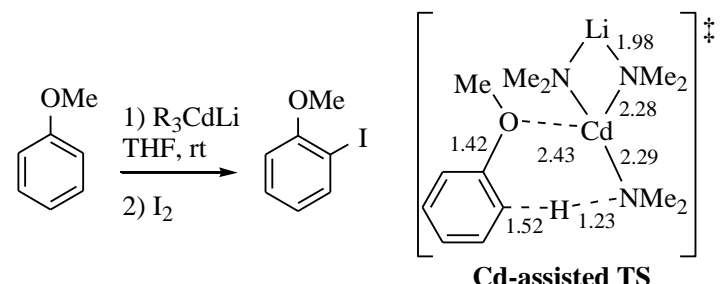

Lithium cadmates bearing different ligands were compared with efficient (TMP) ${ }_{3} \mathrm{CdLi}$ (TMP = 2,2,6,6-tetramethylpiperidino) for their ability to deproto-metalate anisole. The generated arylcadmates were evidenced using $\mathrm{I}_{2}$. The results show that it is possible to replace only one of the TMP (with a piperidino, a diisopropylamino, a butyl or a sec-butyl) without important yield drop. In the light of DFT calculations, reaction pathways were proposed for the deproto-cadmations of anisole using a triamino-, an alkyldiamino-, and an aminodialkyl-cadmate.

The deprotonative metalation has been widely used as a powerful method for the regioselective functionalization of aromatic compounds. ${ }^{1}$ Organolithiums and hindered lithium amides have been largely employed for this purpose because they are either commercially available or can be readily prepared in ethers and alkanes. However, their compatibility with sensitive substrates and functional groups is low. In addition, in the absence of polar solvents such as tetrahydrofuran (THF), activating agents such as $N, N, N^{\prime}, N^{\prime}-$ tetramethylethylene-diamine (TMEDA) or directing groups able to disaggregate the base, the efficiency of reactions using lithium compounds on their own as bases is limited.

The use of metal additives in order to modify the behavior of bases is a challenging field. Various $(R)_{n}\left(R^{\prime}\right)_{n^{\prime}} \mathrm{MLi}(\mathrm{M}=$ metal, R, R' = alkyl, amino, chloro...) type compounds already prepared behave as superbases since such species exhibit behaviors that cannot be reproduced by the monometallic compounds on their own. Well-known examples of powerful RR'MLi mixtures of organolithiums and $\mathrm{M}$ alkali metal alkoxides are LIC-KOR (LIC = (common) $\mathrm{BuLi}, \mathrm{KOR}=$ potassium tert-butoxide) first described by Schlosser $^{2}$ and Lochmann, ${ }^{3}$ and BuLi-LiDMAE (DMAE = 2-dimethylaminoethoxide) developed in the pyridine series by Gros and Fort. ${ }^{4}$ $(\mathrm{R})_{\mathrm{n}}\left(\mathrm{R}^{\prime}\right)_{\mathrm{n}} \mathrm{MLi}$ type bases with $\mathrm{M}$ different from an alkali metal have also been described since by different groups. ${ }^{5}$ Among them, examples are the mixed $\mathrm{Li}-\mathrm{Zn}$ bases $\mathrm{R}_{2} \mathrm{Zn}(\mathrm{TMP}) \mathrm{Li}$ ( TMEDA) $\left(\mathrm{R}={ }^{t} \mathrm{Bu}, \mathrm{Bu}\right)$ described by the groups of Kondo, Uchiyama, Mulvey and Hevia, ${ }^{6}$ and $(\mathrm{TMP})_{2} \mathrm{Zn} \cdot 2 \mathrm{MgCl}_{2} \cdot 2 \mathrm{LiCl}^{7}$ and TMPZnCl $\cdot \mathrm{LiCl}^{8}$ developed by the group of Knochel.

We recently developed a mixed $\mathrm{Li}-\mathrm{Cd}$ base, $(\mathrm{TMP})_{3} \mathrm{CdLi}$, which allowed efficient and chemoselective reactions. ${ }^{9}$ This base was easily prepared by mixing $\mathrm{CdCl}_{2}$. TMEDA with 3 equiv of LiTMP, and its ate structure has been shown on the basis of NMR spectroscopy and DFT calculation studies. In order to identify the structural requirements to meet in order to get an efficient metalation, the deprotonation ability of different $(\mathrm{R})_{\mathrm{n}}\left(\mathrm{R}^{\prime}\right)_{(3-\mathrm{n})} \mathrm{CdLi}$ compounds was investigated.

The metalation of anisole by (TMP $)_{3} \mathrm{CdLi}(0.5$ equivalent of $\mathrm{CdCl}_{2} \cdot$ TMEDA and 1.5 equivalents of LiTMP) in THF at room temperature for $2 \mathrm{~h}$, followed by subsequent trapping with $\mathrm{I}_{2}$, proceeds in $75 \%$ yield (Table 1 , entry 1 ). ${ }^{10}$ Amines such as piperidine, diisopropylamine and even 1,1,1,3,3,3hexamethyldisilazane are less expensive than HTMP, and the use of the corresponding amino groups in homo- and heteroleptic bases was considered as a cheaper alternative to $(\mathrm{TMP})_{3} \mathrm{CdLi}$. Putative $(\mathrm{P})_{3} \mathrm{CdLi}(\mathrm{P}=$ piperidino $)$ and $(\text { HMDS })_{3} \mathrm{CdLi}$ (HMDS = bis(trimethylsilyl)-amino) failed in metalating anisole (entries 2,3). In contrast, expected 2iodoanisole was isolated in $42 \%$ yield with (DA) ${ }_{3} \mathrm{CdLi}(\mathrm{DA}=$ $\mathrm{N}^{\mathrm{i}} \mathrm{Pr}_{2}$ ), but provided that 1 equiv is used (entry 4$) .{ }^{11}$

The use of heteroleptic $\mathrm{Li}-\mathrm{Cd}$ amides bearing one or two TMP ligand(s) was then attempted. It was found possible to replace one of the three TMP groups of (TMP) ${ }_{3} \mathrm{CdLi}$ with a piperidino group without altering the efficiency of the reaction (entry 5). In contrast, the use of one or two HMDS groups resulted in low yields (entries 6,7). As observed by replacing one TMP with a piperidino, the use of one DA group for two remaining TMP proved efficient, affording the iodide in $84 \%$ yield (entry 8 ). The replacement of a second TMP led to a low conversion of anisole; the $39 \%$ yield obtained with (TMP)Cd(DA) $)_{2} \mathrm{Li}$ (entry 9) is similar to that of $42 \%$ observed using (DA) $)_{3} \mathrm{CdLi}$.

TABLE 1. Metalation of Anisole Using Different Homo- and Heteroleptic Li-Cd Amides Followed by Trapping with $\mathbf{I}_{2}$.

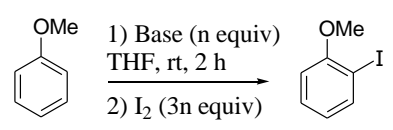

\begin{tabular}{|c|c|c|c|c|c|}
\hline entry & base $(n)$ & yield & entry & $\operatorname{base}^{a}(\mathrm{n})$ & yield \\
\hline 1 & $(\mathrm{TMP})_{3} \mathrm{CdLi}(0.5)$ & $75 \%$ & $\overline{5}$ & $(\mathrm{P}) \mathrm{Cd}(\mathrm{TMP})_{2} \mathrm{Li}(1)$ & $75 \%$ \\
\hline 2 & $(\mathrm{P})_{3} \mathrm{CdLi}^{a}(1)$ & $0 \%$ & 6 & $(\mathrm{HMDS}) \mathrm{Cd}(\mathrm{TMP})_{2} \mathrm{Li}(1)$ & $21 \%$ \\
\hline 3 & $(\mathrm{HMDS})_{3} \mathrm{CdLi}^{a}(1)$ & $0 \%$ & 7 & $(\mathrm{TMP}) \mathrm{Cd}(\mathrm{HMDS})_{2} \mathrm{Li}$ (1) & $3 \%$ \\
\hline 4 & $(\mathrm{DA})_{3} \mathrm{CdLi}^{a}(1)$ & $42 \%$ & 8 & $(\mathrm{DA}) \mathrm{Cd}(\mathrm{TMP})_{2} \mathrm{Li}(1)$ & $84 \%$ \\
\hline \multicolumn{3}{|c|}{${ }^{a}$ Putative base. } & 9 & $(\mathrm{TMP}) \mathrm{Cd}(\mathrm{DA})_{2} \mathrm{Li}(1)$ & $39 \%$ \\
\hline
\end{tabular}

$(\mathrm{TMP})_{3} \mathrm{CdLi}$ was next compared with $\mathrm{RCd}(\mathrm{TMP})_{2} \mathrm{Li}$ and $\mathrm{R}_{2} \mathrm{Cd}(\mathrm{TMP}) \mathrm{Li}(\mathrm{R}=$ alkyl, Table 2 ). By replacing one TMP group with one butyl, the metalation of anisole still took place 
efficiently, but provided that 1 equiv of base is used (entries 1,2). ${ }^{11}$ Decidedly lower yields, decreasing with the number of TMP groups, were obtained employing $\mathrm{Bu}_{2} \mathrm{Cd}(\mathrm{TMP}) \mathrm{Li}$ and $\mathrm{Bu}_{3} \mathrm{CdLi}$ (entries 3-5). Similar results were observed by replacing TMP groups of (TMP) ${ }_{3} \mathrm{CdLi}$ with sec-butyl groups (entries 6,7). With tert-butyl (entries 8,9) and trimethylsilylmethyl (entries 10-12) groups, yields still decrease with increasing numbers of alkyl groups but, in these cases, the reaction efficiency is poorer than observed with butyl and sec-butyl groups.

TABLE 2. Metalation of Anisole Using Mixed Alkyl-Amino Li-Cd Amides Followed by Trapping with $\mathbf{I}_{2}$.

\begin{tabular}{|c|c|c|c|c|c|}
\hline entry & putative base (n) & yield & entry & putative base (n) & yield \\
\hline 1 & $\mathrm{BuCd}(\mathrm{TMP})_{2} \mathrm{Li}(0.5)$ & 34 & 7 & ${ }^{s} \mathrm{Bu}_{2} \mathrm{Cd}(\mathrm{TMP}) \mathrm{Li}(1)$ & 8 \\
\hline 2 & $\mathrm{BuCd}(\mathrm{TMP})_{2} \mathrm{Li}(1)$ & 78 & 8 & ${ }^{t} \mathrm{BuCd}(\mathrm{TMP})_{2} \mathrm{Li}(1)$ & 39 \\
\hline 3 & $\mathrm{Bu}_{2} \mathrm{Cd}(\mathrm{TMP}) \mathrm{Li}(0.5)$ & 7 & 9 & ${ }^{t} \mathrm{Bu}_{2} \mathrm{Cd}(\mathrm{TMP}) \mathrm{Li}(1)$ & 3 \\
\hline 4 & $\mathrm{Bu}_{2} \mathrm{Cd}(\mathrm{TMP}) \mathrm{Li}(1)$ & 28 & 10 & $\mathrm{TMSCH}_{2} \mathrm{Cd}(\mathrm{TMP})_{2} \mathrm{Li}(1)$ & 51 \\
\hline 5 & $\mathrm{Bu}_{3} \mathrm{CdLi}(0.5)$ & 9 & 11 & $\left(\mathrm{TMSCH}_{2}\right)_{2} \mathrm{Cd}(\mathrm{TMP}) \mathrm{Li}$ (1) & 13 \\
\hline 6 & ${ }^{s} \mathrm{BuCd}(\mathrm{TMP})_{2} \mathrm{Li}(1)$ & 75 & 12 & $\left(\mathrm{TMSCH}_{2}\right)_{3} \mathrm{CdLi}(1)$ & 0 \\
\hline
\end{tabular}

The deprotonative metalation using cadmate bases was theoretically investigated using DFT calculations. To this purpose, $\left(\mathrm{Me}_{2} \mathrm{~N}\right)_{3} \mathrm{CdLi}, \mathrm{MeCd}\left(\mathrm{NMe}_{2}\right)_{2} \mathrm{Li}$ and $\mathrm{Me}_{2} \mathrm{Cd}\left(\mathrm{NMe}_{2}\right) \mathrm{Li}$ were respectively employed as models for $(\mathrm{TMP})_{3} \mathrm{CdLi}$, $\mathrm{RCd}(\mathrm{TMP})_{2} \mathrm{Li}$ and $\mathrm{R}_{2} \mathrm{Cd}(\mathrm{TMP}) \mathrm{Li}$. A molecule of $\mathrm{Me}_{2} \mathrm{O}$ (instead of THF) was incorporated to complete lithium atom coordination. Although the choice of this simplified model system may lead to an underestimation of the steric effects of bulky groups, the essential character of the reaction should still be observable using this model system.

Reaction Pathway of Deprotonation of Anisole with Lithium tris(Dimethylamino)cadmate (Figure 1). Among several possibilities for the deprotonation reaction using $\left(\mathrm{Me}_{2} \mathrm{~N}\right)_{3} \mathrm{CdLi}$, we identified two plausible reaction pathways through Li-assisted and Cd-assisted deprotonation TSs (TS1 and TS2). In both cases, the reaction coordinates started with formation of a relatively stable initial complex (IM1 or IM2) between anisole oxygen and the counter cation $\mathrm{Li}$ or the central $\mathrm{Cd}$ metal. This indicated that the regioselectivity of the ortho cadmation reaction can be explained by a coordinative approximation effect between functional group and the $\mathrm{Li}$ or $\mathrm{Cd}$ metal, enabling initial complex formation and orienting the ate base ligand exclusively toward aromatic ortho hydrogen. The Li-assisted deprotonation (path 1) is a similar pathway to that seen in TMP-Zn-ate mediated DoM reactions, ${ }^{6 g}$ and takes place via "open form TS" (TS1) with a reasonable activation energy $(+22.0 \mathrm{kcal} / \mathrm{mol})$. The $\mathrm{Cd}$-assisted deprotonation (path 2), an unique pathway of this Cd-ate base, proceeds smoothly with a smaller activation energy (19.5 kcal $/ \mathrm{mol})$. This deprotonation is facilitated by the direct push-pull synergy of the Lewis acidic $\mathrm{Cd}$ metal and the negatively charged $\mathrm{NMe}_{2}$ moiety to generate a stable product (PD2). The stabilization energy is very large $(-26.8 \mathrm{kcal} / \mathrm{mol})$, because this deprotonation occurs with maintenance of the stable $\mathrm{Me}_{2} \mathrm{~N}^{\cdots} \mathrm{Li}^{\cdots} \mathrm{NMe}_{2}$ coordination.

FIGURE 1. Reactants, Intermediates, Complexes, and TSs in the Deprotonation Reaction of Anisole with $\left(\mathrm{Me}_{2} \mathrm{~N}\right)_{3} \mathrm{CdLi}$. Bond Lengths and Energy Changes at the B3LYP/631SVPs Level are shown in $\AA$ and kcal/mol, respectively.

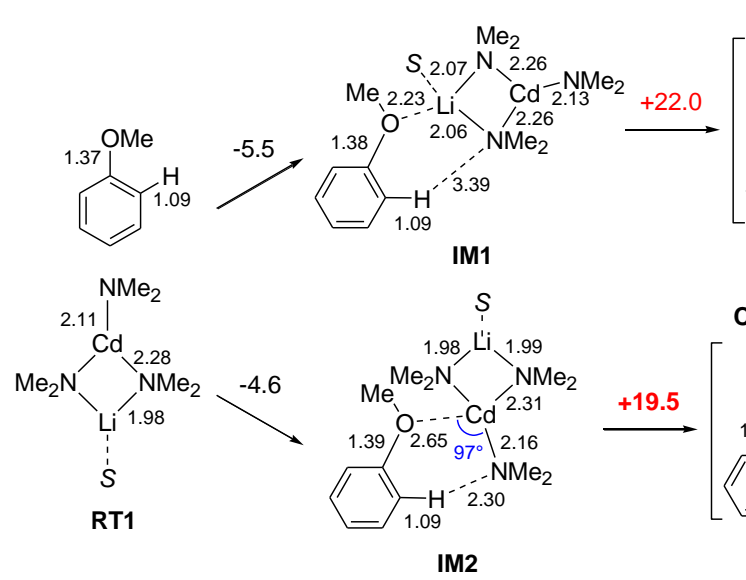

Li-assisted TS (path 1)

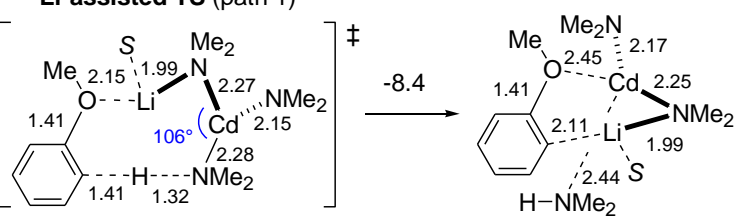

TS1

PD1

Cd-assisted TS (path 2)

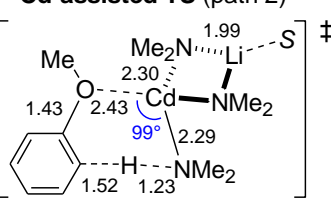

TS2

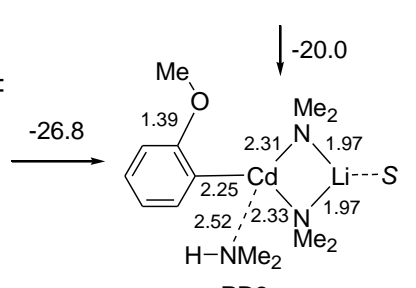

PD2
Reaction Pathway of Deprotonation of Anisole with Lithium bis(Dimethylamino)alkylcadmate (Figure 2). The computational results of deprotonation with $\mathrm{MeCd}\left(\mathrm{NMe}_{2}\right)_{2} \mathrm{Li}$ indicated that the Li-assisted pathway via the "open form" TS (path 3) is the most probable. In this pathway, the DoM reaction proceeds through $\mathbf{T S 3}$ by using one of the $\mathrm{Me}_{2} \mathrm{~N}$ ligands of $\mathrm{MeCd}\left(\mu-\mathrm{NMe}_{2}\right)_{2} \mathrm{Li}$ (in RT2). The activation energy of path 3 is $4.4 \mathrm{kcal} / \mathrm{mol}$ higher than that of the Cd-assisted pathway (path 2) in the reaction with $\left(\mathrm{Me}_{2} \mathrm{~N}\right)_{3} \mathrm{CdLi}$. This calculation indicates that the reaction of $\mathrm{RCd}(\mathrm{TMP})_{2} \mathrm{Li}$ (Table 2 , entry 2) proceeds as well as the reaction of (TMP) ${ }_{3} \mathrm{CdLi}$. The reaction pathway via the "closed form" TS4 (path 4) is rather unfavorable. A Cd-assisted deprotonation pathway (path 5) was also identified and the activation energy (+20.2 $\mathrm{kcal} / \mathrm{mol}$ ) is energetically more favorable than that of the Liassisted "open form" pathway (path 3) by $3.7 \mathrm{kcal} / \mathrm{mol}$ because of direct activation of the $\mathrm{Cd}-\mathrm{N}$ bond by anisole oxygen. This pathway, however, first requires the reformation of the most stable symmetric cadmate in RT2 to an unstable unsymmetric one in RT3, including the dissociation of the stable $\mathrm{Li}^{\cdots} \mathrm{N}$ bond - a process leading the $16.2 \mathrm{kcal} / \mathrm{mol}$ loss of energy. Therefore, this pathway is much less likely to take place than those of $\mathrm{Li}$-assisted deprotonation shown in Figure 2. 
FIGURE 2. Reactants, Intermediates, Complexes, and TSs in the Deprotonation Reaction of Anisole with $\left.\mathrm{MeCd}_{(\mathrm{NMe}}\right)_{2} \mathrm{Li}$. See Figure 1 for details.

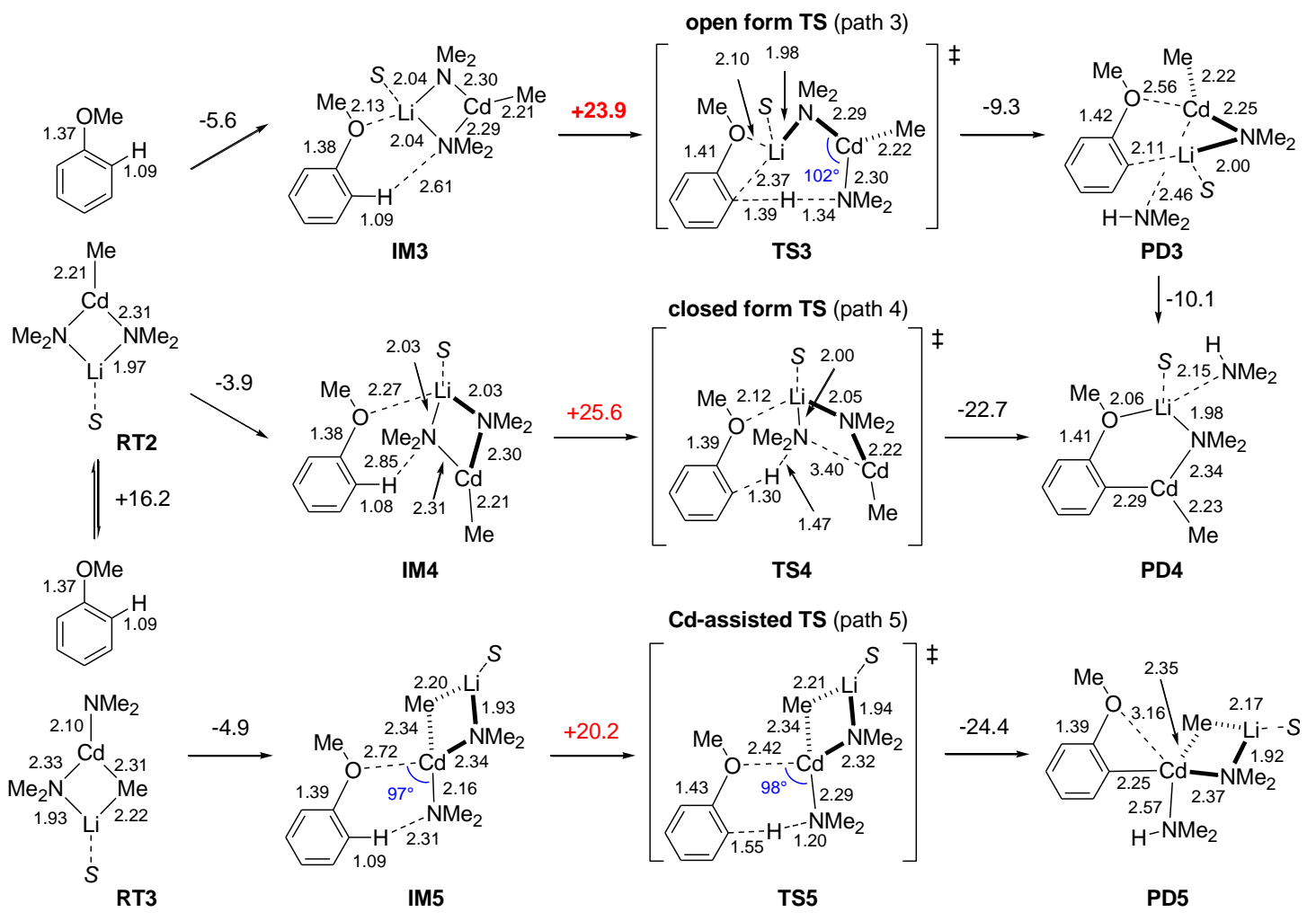

Reaction Pathway of Deprotonation of Anisole with Lithium Dialkyl(dimethylamino)cadmate (Figure 3). Two structures are also a priori possible for $\mathrm{Me}_{2} \mathrm{Cd}\left(\mathrm{NMe}_{2}\right) \mathrm{Li}$, i.e. the unsymmetrical one (in RT4) and the symmetrical one (in RT5): the former structure is computed to be much more stable, mainly due to the stable $\mathrm{Me}_{2} \mathrm{~N}^{\cdots} \mathrm{Li}$, than the latter one by $17.0 \mathrm{kcal} / \mathrm{mol}$. Initial electrostatic coordination of $\mathrm{Li}$ to anisole oxygen occurs, resulting in the formation of a complex (IM6) with a stabilization energy of $7.4 \mathrm{kcal} / \mathrm{mol}$. From IM6, the DoM reaction using the $\mathrm{Me}_{2} \mathrm{~N}$ ligand can take two pathways through TS6 ("closed form" TS, path 6) and TS7 ("open form" TS, path 7). Although the activation energies are only $0.7 \mathrm{kcal} / \mathrm{mol}$ higher than that of the DoM reaction with $\operatorname{MeCd}\left(\mu-\mathrm{NMe}_{2}\right)_{2} \mathrm{Li}$ (path 3), the deprotonation occurs with more than $10 \mathrm{kcal} / \mathrm{mol}$ endothermicity. This large energy loss is a result of the cleavage of the stable $\mathrm{Me}_{2} \mathrm{~N}^{\cdots} \mathrm{Li}$ bond and of the rather small energy gain to form a $\mathrm{C}^{\cdots} \mathrm{Li}$ bond at the expense of the $\mathrm{Me}_{2} \mathrm{~N}^{\cdots} \mathrm{Li}$ bond cleavage. These results indicate that path 6 and 7 are kinetically favored but thermodynamically unfavored. The computed predilection accounts for the experimental observation that dialkylamidocadmate complexes are almost inert in the deprotonative cadmation reaction of anisole (Table 2, entries 3 and 4). Deprotonation by the $\mu$-Me ligand on $\mathrm{Cd}$ (path 8 ) was also found to be kinetically unfavorable, requiring a much higher activation energy of $32.7 \mathrm{kcal} / \mathrm{mol}$.

In summary, among all the homo- and heteroleptic Li-Cd amides tested, (TMP) ${ }_{3} \mathrm{CdLi}$ was the more efficient reagent; by replacing one TMP with a piperidino or a diisopropylamino

group, similar yields were obtained but with a double amount of base, as if piperidino and diisopropylamino were unable to act as bases. A ligand of (TMP $)_{3} \mathrm{CdLi}$ could be replaced in the same way with a butyl or a sec-butyl group.

From the mechanistic point of view, the DFT calculations revealed that the metalation with $(\mathrm{TMP})_{3} \mathrm{CdLi}$ proceeds through a $\mathrm{Cd}$-assisted transition state while pathways with higher activation energies and Li-assisted transition states were found with $\mathrm{RCd}(\mathrm{TMP})_{2} \mathrm{Li}$ and $\mathrm{R}_{2} \mathrm{Cd}(\mathrm{TMP}) \mathrm{Li}(\mathrm{R}=$ alkyl). The mechanism of the anisole deprotonation using TMPdialkyl zincates has been the subject of studies. ${ }^{6 \mathrm{~g}, \mathrm{i}}$ A two-step mecanism has been proposed where the lithium zincate first acts as an amino base, and thus generated HTMP then returns back to zinc through 2-anisyl- or R-mediated deprotonation. Studies will be soon started in order to identify the species present in reaction mixtures coming from metalation steps using $\mathrm{Li}-\mathrm{Cd}$ combinations, and to possibly propose more complete mechanisms.

(TMP) ${ }_{3} \mathrm{CdLi}$ proved to allow amazing reactions such as the dideprotonation of sensitive pyrazine ${ }^{12}$ and ferrocene esters, ${ }^{13}$ which cannot be achieved using other $(R)_{n}\left(R^{\prime}\right)_{n^{\prime}} M L i$ type bases. To overcome concerns about inherent toxicity of cadmium compounds, ${ }^{14}$ new mixed Li-metal bases of ate type are under development.

Experimental Section. All bases were synthesized from $\mathrm{CdCl}_{2} \cdot$ TMEDA. $^{15}$

Computational Details. All calculations were carried out with the Gaussian 03 program package. ${ }^{16}$ The molecular 
structures and harmonic vibrational frequencies were obtained using the hybrid density functional method based on Becke's three-parameter exchange function and the Lee-Yang-Parr nonlocal correlation functional (B3LYP). ${ }^{17}$ We used Ahlrichs' $\mathrm{SVP}^{18}$ all-electron basis set for the cadmium atom and 6$31 \mathrm{G}^{*}$ for the other atoms (denoted as 631SVPs in the text). Geometry optimization and vibrational analysis were performed at the same level. All stationary points were optimized without any symmetry assumptions, and characterized by normal coordinate analysis at the same level of theory (number of imaginary frequencies, NIMAG, 0 for minima and 1 for TSs).

FIGURE 3. Reactants, Intermediates, Complexes, and TSs in the Deprotonation Reaction of Anisole with $\mathrm{Me}_{2} \mathrm{Cd}\left(\mathrm{NMe}_{2}\right) \mathrm{Li}$. See Figure 1 for details.

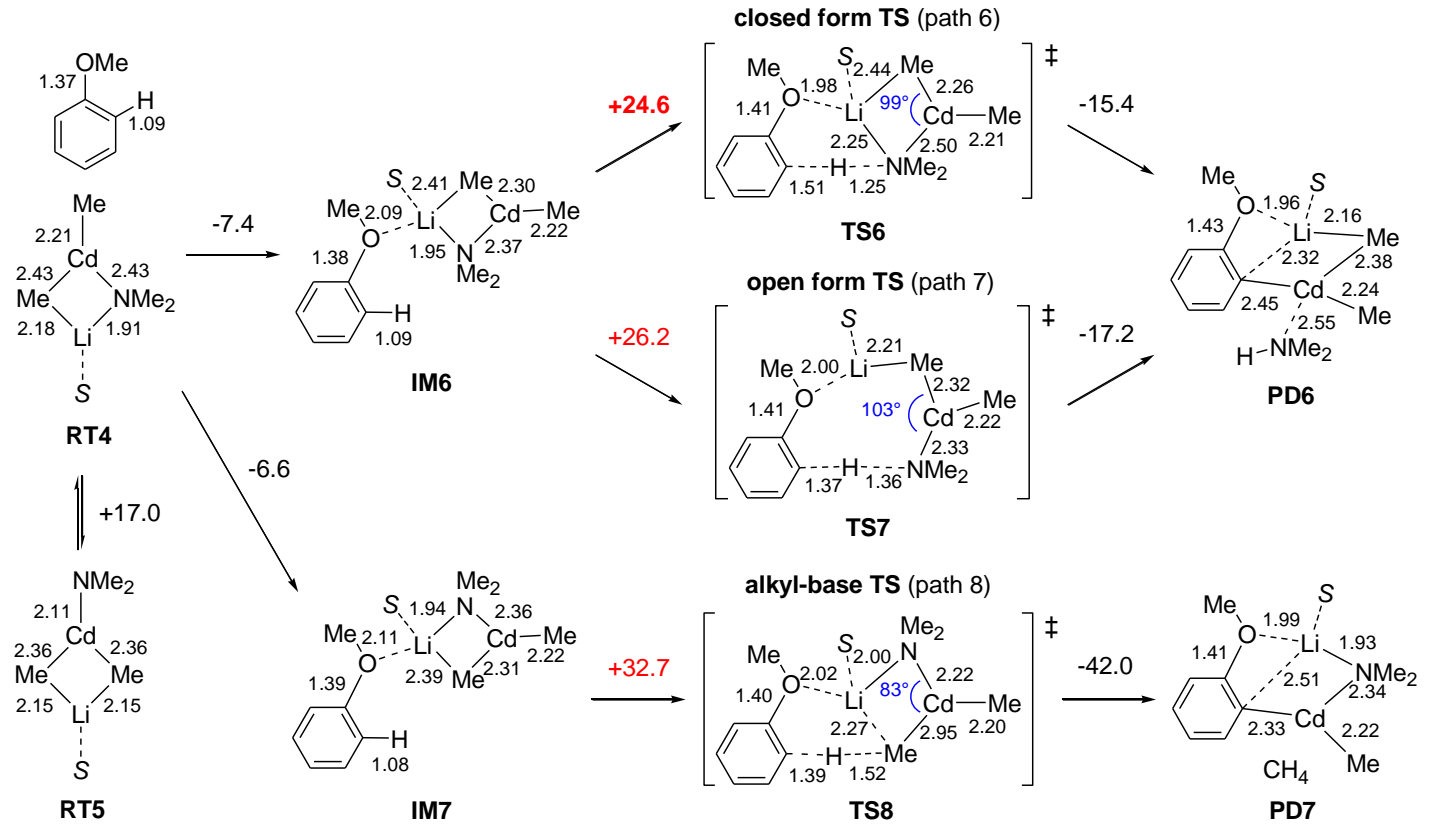

Acknowledgements. The authors gratefully acknowledge the financial support of Région Bretagne (to K. S.) and Agence Nationale de la Recherche (ACTIVATE program) to K. S. and M. U.). The calculations were performed by using the RIKEN Integrated Cluster of Clusters (RICC) facility.

Supporting Information Available: Experimental procedures, computational methods, cartesian coordinates and total electron energies. This material is available free of charge via the Internet at http://pubs.acs.org.

(1) For excellent reviews, see: (a) Gschwend, H. W.; Rodriguez, H. R. Org. React. 1979, 26, 1-360; (b) Beak, P.; Snieckus, V. Acc. Chem. Res. 1982, 15 306-312; (c) Snieckus, V. Chem. Rev. 1990, 90, 879-933; (d) Gant, T. G.; Meyers, A. I. Tetrahedron 1994, 50, 2297-2360; (e) Schlosser, M. in Organometallics in Synthesis, $2^{\text {nd }}$ ed. (Ed.: M. Schlosser), Wiley, 2002 Chapter I.

(2) Schlosser, M. Pure Appl. Chem. 1988, 60, 1627-1634.

(3) Lochmann, L. Eur. J. Inorg. Chem. 2000, 7, 1115-1126.

(4) Gros, P. C.; Fort, Y. Eur. J. Org. Chem. 2009, 4199-4209.

(5) For reviews, see: (a) Mulvey, R. E. Organometallics 2006, 25, 10601075; (b) Mulvey, R. E.; Mongin, F.; Uchiyama, M.; Kondo, Y. Angew. Chem Int. Ed. 2007, 46, 3802-3824; (c) Mulvey, R. E. Acc. Chem. Res. 2009, 42 743-755.

(6) (a) Kondo, Y.; Shilai, M.; Uchiyama, M.; Sakamoto, T. J. Am. Chem. Soc. 1999, 121, 3539-3540. (b) Uchiyama, M.; Miyoshi, T.; Kajihara, Y.; Sakamoto, T.; Otani, Y.; Ohwada, T. Kondo, Y. J. Am. Chem. Soc. 2002, 124 8514-8515. (c) Barley, H. R. L.; Clegg, W.; Dale, S. H.; Hevia, E.; Honeyman, G. W.; Kennedy, A. R.; Mulvey, R. E. Angew. Chem. Int. Ed. 2005, 44, 6018 6021. (d) Clegg, W.; Dale, S. H.; Hevia, E.; Honeyman, G. W.; Mulvey, R. E. Angew. Chem. Int. Ed. 2006, 45, 2370-2374. (e) Clegg, W.; Dale, S. H.; Harrington, R. W.; Hevia, E.; Honeyman, G. W.; Mulvey, R. E. Angew. Chem.

Int. Ed. 2006, 45, 2374-2377. (f) Clegg, W.; Dale, S. H.; Drummond, A. M.; Hevia, E.; Honeyman, G. W.; Mulvey, R. E. J. Am. Chem. Soc. 2006, 128 7434-7435. (g) Uchiyama, M.; Matsumoto, Y.; Nobuto, D.; Furuyama, T.; Yamaguchi, K.; Morokuma, K. J. Am. Chem. Soc. 2006, 128, 8748-8750. (h) Uchiyama, M.; Kobayashi, Y.; Furuyama, T.; Nakamura, S.; Kajihara, Y.; Miyoshi, T.; Sakamoto, T.; Kondo, Y.; Morokuma, K. J. Am. Chem. Soc. 2008, 130, 472-480. (i) Clegg, W.; Conway, B.; Hevia, E.; McCall, M. D. Russo, L.; Mulvey, R. E. J. Am. Chem. Soc. 2009, 131, 2375-2384.

(7) (a) Wunderlich, S. H.; Knochel, P. Angew. Chem. Int. Ed. 2007, 46, 7685-7688. (b) Wunderlich, S.; Knochel, P. Chem. Commun. 2008, 63876389. (c) Wunderlich, S. H.; Knochel, P. Org. Lett. 2008, 10, 4705-4707. (d) Mosrin, M.; Knochel, P. Chem. Eur. J. 2009, 15, 1468-1477.

(8) Mosrin, M.; Knochel, P. Org. Lett. 2009, 11, 1837-1840.

(9) (a) L'Helgoual'ch, J.-M.; Bentabed-Ababsa, G.; Chevallier, F.; Yonehara, M.; Uchiyama, M.; Derdour, A.; Mongin, F. Chem. Commun. 2008, 5375-5377. (b) Snégaroff, K.; L'Helgoual'ch, J.-M.; Bentabed-Ababsa, G.; Nguyen, T. T.; Chevallier, F.; Yonehara, M.; Uchiyama, M.; Derdour, A.; Mongin, F. Chem. Eur. J. 2009, 15, 10280-10290.

(10) The synergy of the reaction was demonstrated using either LiTMP or $(\mathrm{TMP})_{2} \mathrm{Cd}$; see Ref. 10

(11) The $75 \%$ yield obtained using 0.5 equiv of (TMP) $)_{3} \mathrm{CdLi}$ were not equaled using 0.5 equiv of every one of the other Li-Cd combinations used. Similar results were obtained in some cases but provided that 1 equiv of base is used.

(12) L'Helgoual'ch, J.-M.; Bentabed-Ababsa, G.; Chevallier, F.; Derdour, A.; Mongin, F. Synthesis 2008, 4033-4035.

(13) Dayaker, G.; Sreeshailam, A.; Chevallier, F.; Roisnel, T.; Radha Krishna, P.; Mongin, F. Chem. Commun. 2010, DOI: 10.1039/b924939g.

(14) Shannon, M. Heavy Metal Poisoning in Clinical Management of Poisoning and Drug Overdose, $3^{\text {rd }}$ ed. (Eds: Haddad, L. M.; Shannon, M.; Winchester, J. F.), 1998

(15) Kedarnath, G.; Kumbhare, L. B.; Jain, V. K.; Phadnis, P. P.; Nethaji, M. Dalton Trans. 2006, 2714-2718.

(16) Frisch, M. J. et al. Gaussian 03, Revision E.01; Gaussian, Inc.: Wallingford, CT, 2004. 
(17) (a) Becke, A. D. Phys. Rev. 1988, A38, 3098-3100. (b) Becke, A. D. J. Chem. Phys. 1993, 98, 1372-1377. (c) Becke, A. D. J. Chem. Phys. 1993, 98 5648-5652. (d) Lee, C.; Yang, W.; Parr, R. G. Phys. Rev. 1988, B37, 785-788.

(18) Schäfer, A.; Horn, H.; Ahlrichs, R. J. Chem. Phys. 1992, 97, 25712577. 